\title{
Nota Científica: Ultrafiltração de efluente da indústria de laticínios para recuperação de nutrientes: efeito da pressão e da velocidade tangencial
}

\author{
Scientific Note: Ultrafiltration of effluents from a dairy industry for nutrient recovery:
} effect of pressure and tangential velocity

\section{Autores | Authors}

凶Vandré Barbosa BRIÃO

Universidade de Passo Fundo (UPF) Faculdade de Engenharia e Arquitetura Departamento de Engenharia de Alimentos Campus I, São José Rod. BR 285, Km 171 Caixa Postal: 611 CEP: $99052-900$

Passo Fundo/RS - Brasil e-mail:vandre@upf.br

\section{Célia Regina Granhen TAVARES}

Universidade Estadual de Maringá (UEM) Departamento de Engenharia Química Maringá/PR - Brasil e-mail:celia@deq.uem.br

$\triangle$ Autor Correspondente / Corresponding Author

Recebido / Received: 08/10/2010 Aprovado / Approved: 22/08/2012 Publicado / Published: dez./2012

\section{Resumo}

O processo de limpeza da indústria de laticínios gera elevados volumes de efluente, chegando-se a produzir $10 \mathrm{~L}$ de efluente por litro de leite processado. A água do primeiro enxágue pode arrastar de 1\% a 3\% de sólidos de leite, representando custos de produção. A ultrafiltração pode ser utilizada para recuperar estes sólidos, visando reinseri-los no processo. O objetivo deste trabalho foi testar o processo de ultrafiltração utilizando-se duas membranas com diferentes geometrias (tubular e espiral), em diferentes condições de pressão e velocidade tangencial, para recuperar e concentrar estes sólidos do leite, buscando obter um composto lácteo passível de ser reutilizado. O processo foi avaliado e otimizado utilizando-se uma água de enxágue modelo $\left(1,7 \mathrm{~g} \cdot \mathrm{L}^{-1}\right.$ de leite em pó integral diluído em água potável), alimentada por um sistema de ultrafiltração tangencial, variando-se a pressão (98; 196 e $294 \mathrm{kPa}$ para ambas as membranas) e a velocidade tangencial $\left(0,79 ; 1,42 ; 2,23 \mathrm{~m} . \mathrm{s}^{-1}\right.$ para a membrana tubular e 0,15 ; 0,$27 ; 0,44 \mathrm{~m} . \mathrm{s}^{-1}$ para a membrana espiral), por meio de um planejamento fatorial $3^{2}$. Usou-se como variáveis de resposta o fluxo permeado e as concentrações de proteína, óleos e graxas, lactose, fósforo e cálcio do permeado, bem como a Demanda Química de Oxigênio (DQO). A condição experimental otimizada para a membrana tubular foi obtida com a pressão de $294 \mathrm{kPa}$ (elevando a rejeição

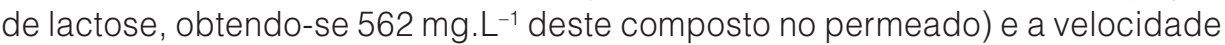
tangencial de 2,23 m. $\mathrm{s}^{-1}$ (elevando o fluxo permeado, obtendo-se $93,2 \mathrm{~kg} \cdot \mathrm{m}^{-2} \cdot \mathrm{h}^{-1}$, e reduzindo a concentração de óleos e graxas para $39 \mathrm{mg} \cdot \mathrm{L}^{-1}$ no permeado). Quanto à membrana espiral, a pressão e a velocidade tangencial exerceram efeito somente sobre o fluxo permeado (obtendo-se $34,8 \mathrm{~kg} \cdot \mathrm{m}^{-2} \cdot \mathrm{h}^{-1}$ ), não havendo efeito significativo sobre as demais variáveis de resposta. $\mathrm{O}$ processo realizado com essa membrana foi otimizado com a pressão de $294 \mathrm{kPa}$ e 0,44 m.s $\mathrm{s}^{-1}$. A rejeição de ambas as membranas foi superior a 70\% para a DQO, 94\% para proteínas e acima de $85 \%$ para gordura. A concentração da água de enxágue foi realizada com a membrana espiral, reduzindo-se o seu volume inicial em 34 vezes. 0 concentrado lácteo foi obtido com $2,3 \%$ de sólidos totais, 1,1\% de proteínas e $0,9 \%$ de gordura. A ultrafiltração demonstrou ser um processo viável para a recuperação de sólidos lácteos na indústria de laticínios.

Palavras-chave: Reuso de efluentes; Membranas; Leite. 


\section{Summary}

The cleaning process used in the dairy industry generates a great volume of effluent, engendering up to $10 \mathrm{~L}$ of effluent per litre of milk processed. The first rinsing water can carry off $1 \%-3 \%$ of the milk solids, representing production costs. Ultrafiltration can be used to recover these milk solids aiming to reinsert them into the process. The goal of this work was test two ultrafiltration membranes with different configurations (tubular and spiral) with different pressures and cross-flow velocities to recover and concentrate these milk solids, aiming to obtain a dairy compound capable of reuse. The process was evaluated and optimized using a model rinsing water (1.7 g. $\mathrm{L}^{-1}$ of whole milk powder diluted in tap water), fed to a cross-flow ultrafiltration equipment, varying the pressure (98; 196 and $194 \mathrm{kPa}$ for both membranes) and cross-flow velocities $\left(0.79 ; 1.42 ; 2.23 \mathrm{~m} . \mathrm{s}^{-1}\right.$ for the tubular membrane and $0.15 ; 0.27 ; 0.44 \mathrm{~m} . \mathrm{s}^{-1}$ for the spiral membrane), using a $3^{2}$ factorial design. The dependent variables were the permeate flow rate, the Chemical Oxygen Demand (COD), and the protein, fats and oils, lactose, phosphorus and calcium concentrations in the permeate. The optimized test conditions for the tubular membrane were obtained with a pressure of $294 \mathrm{kPa}$ (raising the lactose rejection $-562 \mathrm{mg} . \mathrm{L}^{-1}$ of this compound in the permeate) and a cross-flow velocity of $2.23 \mathrm{~m} \cdot \mathrm{s}^{-1}$ (increasing the permeate flow rate $-93.2 \mathrm{~kg} \cdot \mathrm{m}^{-2} \cdot \mathrm{h}^{-1}$ and reducing the fats and oils concentration in the permeate to $39 \mathrm{mg}^{-1} \mathrm{~L}^{-1}$. With the spiral membrane, the pressure and cross-flow velocity only affected the permeate flow rate (reaching $34.8 \mathrm{~kg} \cdot \mathrm{m}^{-2} \cdot \mathrm{h}^{-1}$ ) with no significant effect on the other dependent variables. The process carried out with this membrane was optimized with a pressure of $294 \mathrm{kPa}$ and $0.44 \mathrm{~m} . \mathrm{s}^{-1}$. The rejection of both membranes was higher than $70 \%$ for COD, $94 \%$ for protein and above $85 \%$ for fat. The model rinsing water was concentrated with the spiral membrane, reducing the initial volume 34 times. The dairy concentrate obtained had $2.3 \%$ total solids, $1.1 \%$ protein and $0.9 \%$ fat. Ultrafiltration was shown to be a possible process to recover milk solids in the dairy industry.

Key words: Effluent reuse; Membranes; Milk. 
Nota Científica: Ultrafiltração de água de enxágue modelo da indústria de laticínios para a recuperação de nutrientes: efeito da pressão e da velocidade tangencial (ultrafiltração de efluente de laticínios)

BRIÃO, V. B. e TAVARES, C. R. G.

\section{Introdução}

O setor lácteo encontra-se em ampla expansão no Brasil, sendo que a produção nacional cresceu cerca de $40 \%$ na última década, chegando a 29 bilhões de litros de leite, em 2009 (IBGE, 2010). Esta expansão, contudo, pode gerar problemas do ponto de vista ambiental, pois as indústrias de laticínios consomem grandes volumes de água para o processamento de seus produtos e a limpeza de seus equipamentos.

A sanitização dos laticínios inclui operações de lavagens de silos, tubulações, tanques, pasteurizadores e equipamentos, que demandam grandes volumes de água (BRIÃO, 2007). Esta água utilizada no enxágue de equipamentos vem a se tornar efluente, fazendo com que esta indústria descarte substantivos volumes de efluentes com alta carga orgânica (BASKARAN et al., 2003; VOURCH et al., 2005). Em alguns casos, cada litro de leite processado pode gerar até dez litros de efluente, que são enviados às estações de tratamento (VOURCH et al., 2005); estima-se que as perdas podem atingir de $1 \%$ a $3 \%$ do volume de leite in natura recebido (VOURCH et al., 2008).

No processo de limpeza dos equipamentos, realiza-se um enxágue inicial e este enxágue arrasta cerca de $90 \%$ da carga orgânica total gerada pela indústria de laticínios. Esta "água branca" compõe-se de um licor de leite diluído, rico em gordura, carboidratos (lactose), proteínas e alguns sais (BALLANEC et al., 2002) e demanda custos com o tratamento de efluentes. Com o aumento da preocupação relacionada ao ambiente, os padrões para avaliação da qualidade do efluente estão cada vez mais restritivos e as indústrias de laticínios deverão investir nos processos in plant de tratamento, vistos como tecnologias limpas e ferramentas de prevenção à poluição (BRIÃO e TAVARES, 2007). Tal iniciativa pode se tornar atrativa do ponto de vista econômico, pois o Brasil implementou uma série de leis e mecanismos nos quais se inserem os conceitos de "usuário pagador" e "poluidor pagador", instituindo-se que se deverá pagar não somente pela captação da água, mas também pelo seu descarte (BRASIL, 1997).

A recuperação de nutrientes presentes nesta "água branca" pode ser uma excelente alternativa do ponto de vista ambiental e econômico, removendo-os da corrente líquida e reduzindo a carga orgânica do efluente, que segue para o tratamento ou a disposição no corpo hídrico; para tanto, os processos de separação por membranas poderiam ser utilizados.

Os processos de separação por membranas (PSM) que utilizam o gradiente de pressão como força motriz (Microfiltração, Ultrafiltração, Nanofiltração e Osmose Inversa) podem ser entendidos como uma extensão da filtração convencional, separando constituintes presentes em solução em nível molecular ou mesmo atômico. A ultrafiltração é o processo pelo qual uma solução é forçada contra uma membrana que permite a passagem do solvente (permeado) e retém solutos de alto peso molecular (retido). As aplicações estão na produção de água potável, no processamento de sucos e laticínios, e no tratamento de efluentes (PEPPIN e ELLIOT, 2001).

Muitos trabalhos com PSM têm sido realizados com o foco no reuso de efluentes de laticínios (BALLANEC et al., 2002, 2005; BASKARAN et al., 2003; CHMIEL et al., 2000; KOYUNCU et al., 2000; MAVROV et al., 2001; TURAN, 2004; SARKAR et al., 2006; VOURCH et al., 2005, 2008). Contudo, os trabalhos têm buscado o reuso do permeado, procurando adequá-lo para a utilização como água de processo. No entanto, deve-se dar também um destino à corrente do retido, pois nela ficarão contidos os sólidos do leite. As informações são escassas - ou mesmo inexistentes - nos meios de divulgação técnico-científica que tratam do assunto sobre o reuso dos sólidos do leite presentes no retido. Em razão dessa falta de informação, a sugestão é destinar estes nutrientes para ração animal (DYRSET et al., 1998), enquanto que estes sólidos lácteos de alto valor biológico poderiam ser reutilizados no processo como insumo de outros derivados, como doce de leite, bebida láctea ou composto lácteo.

A separação dos nutrientes - principalmente proteínas e gordura - por ultrafiltração deve ser realizada em condições operacionais que permitam obter a máxima retenção destes compostos, separando um permeado com menor carga orgânica. A pressão de operação tem efeito direto no fluxo permeado, enquanto que a velocidade tangencial minimiza a polarização de concentração na corrente do retido, e pode refletir tanto no fluxo permeado quanto na eficiência de separação.

O objetivo do trabalho foi avaliar o efeito da pressão e da velocidade tangencial na ultrafiltração de águas de enxágue de laticínios, de modo a otimizar a retenção dos nutrientes presentes nestas águas e recuperá-los para serem reutilizados como insumo de produção de derivados lácteos.

\section{Material e métodos}

\subsection{Procedimento experimental}

O módulo de ultrafiltração utilizado no trabalho é apresentado na Figura 1. O sistema contém um tanque construído em aço inoxidável para a solução de alimentação e uma bomba pneumática, possibilitando a variação da vazão. A pressão foi ajustada por meio da válvula de diafragma e verificada no manômetro localizado na linha de retido. O fluxo foi medido coletando-se o permeado em béqueres, em intervalos de tempo definidos, e pesando-se em balança (fabricante Marte, modelo AS2000C) com precisão de 0,1 mg. A temperatura 
Nota Científica: Ultrafiltração de água de enxágue modelo da indústria de laticínios para a recuperação de nutrientes: efeito da pressão e da velocidade tangencial (ultrafiltração de efluente de laticínios)

BRIÃO, V. B. e TAVARES, C. R. G.

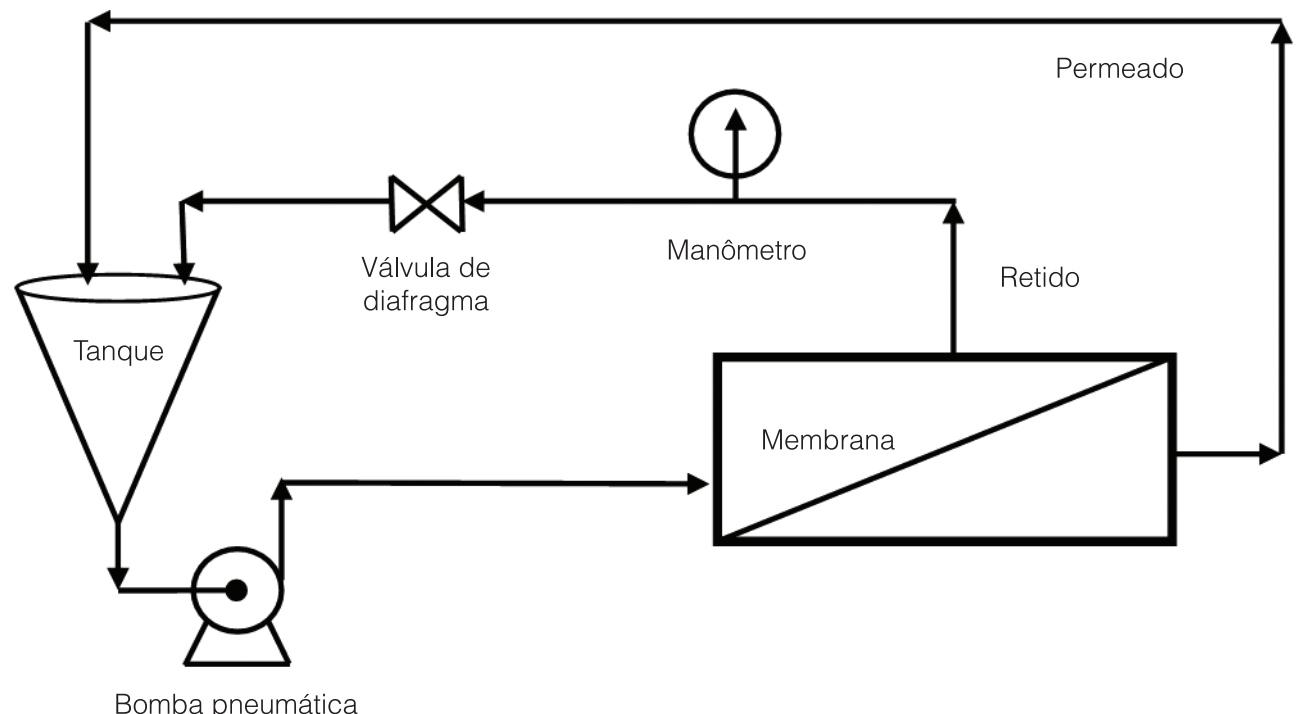

Figura 1. Diagrama do processo de ultrafiltração.

foi $23^{\circ} \mathrm{C} \pm 1^{\circ} \mathrm{C}$, sendo mantida nessa faixa com o auxílio de frascos herméticos de polietileno contendo gelo, os quais eram inseridos no tanque de alimentação.

Duas membranas foram utilizadas de modo a separar proteínas e gorduras do efluente: uma membrana tubular (HFM 180 - Koch Membrane Systems Inc.) de diâmetro de $1,27 \mathrm{~cm}(0,5$ polegada), constituída de fluoreto de polivinilideno (PVDF), com peso molecular de corte de 30 kDa a 80 kDa, e área de $166 \mathrm{~cm}^{2}$; e uma membrana espiral de PES (polieterssulfona), com peso melocular de corte de $5 \mathrm{kDa}$ a $8 \mathrm{kDa}$ e área de 0,28 $\mathrm{m}^{2}$ (HFM 131 - Koch Membrane Systems Inc.). O processo foi operado em batelada, recirculando-se o retido e o permeado.

A água de enxágue foi obtida diluindo-se leite em pó integral em água potável na proporção de 1,7 g.L-1. Essa relação foi testada de modo que a demanda química de oxigênio estivesse próxima de $2000 \mathrm{mg} . \mathrm{L}^{-1}$, valor este encontrado por Brião e Tavares (2007), como característica média de um efluente industrial. A utilização de um efluente modelo é justificada pela necessidade de se alimentar o processo em condições homogêneas, para que as variáveis de resposta não sofram outras influências senão o efeito das variáveis independentes.

Após cada experimento, as membranas eram submetidas ao processo de limpeza realizado no próprio equipamento. Inicialmente, realizou-se um enxágue com água destilada por cerca de 2 minutos, descartando-se o permeado e o retido. Em seguida, foi recirculada uma solução alcalina (solução de $\mathrm{NaOH}$ com pH 10,5) e um novo enxágue foi realizado; uma limpeza ácida (solução de $\mathrm{HNO}_{3} \mathrm{com} \mathrm{pH}$ 2,0) e enxágue final. O tempo de circulação das soluções de limpeza perfez 45 minutos. No término do ciclo de limpeza, era medido o fluxo para comparação com o fluxo inicial com água $\left(\mathrm{J}_{\mathrm{a}}\right)$. Caso esses fluxos não tivessem valores próximos, repetia-se a limpeza alcalina.

\subsection{Coeficiente de colmatação}

O fluxo permeado foi medido com água destilada antes da realização dos experimentos. Após o experimento, um enxágue foi realizado com água destilada, e foi novamente medido o fluxo, calculando-se o Coeficiente de Colmatação (CC) conforme Rao (2002), apresentado na Equação 1.

$$
C C=1-\frac{J_{p}}{J_{a}}
$$

em que: $\mathrm{CC}$ = coeficiente de colmatação (adimensional); $J_{p}=$ fluxo permeado com água após o experimento; $J_{a}=$ fluxo com água antes da realização do experimento.

Observe-se que $0 \leq \mathrm{CC} \leq 1,0$, com o valor mínimo para a membrana limpa e o valor máximo para a membrana completamente bloqueada ao fluxo de permeado.

\subsection{Planejamento dos experimentos}

A otimização do processo foi feita por meio de um planejamento fatorial $3^{2}$ para cada membrana testada, cujas variáveis independentes foram a pressão e a velocidade tangencial. O Quadro 1 apresenta a matriz do planejamento experimental com os valores de pressões e velocidades tangenciais aplicadas nos experimentos realizados com a membrana de geometria tubular.

Para a membrana espiral, as velocidades tangenciais foram 0,$15 ; 0,27$ e 0,44 m.s $\mathrm{s}^{-1}$, e os mesmos 
Nota Científica: Ultrafiltração de água de enxágue modelo da indústria de laticínios para a recuperação de nutrientes: efeito da pressão e da velocidade tangencial (ultrafiltração de efluente de laticínios)

BRIÃO, V. B. e TAVARES, C. R. G.

valores de pressão (98; 196; 294 kPa), totalizando nove condições experimentais para cada membrana. Os experimentos foram realizados em duplicata, totalizando 18 experimentos para cada membrana. A ordem de realização foi aleatória.

Quadro 1. Matriz do planejamento experimental para os ensaios realizados com a membrana de geometria tubular.

\begin{tabular}{|ccc|}
\hline Número do experimento & $\mathbf{p}(\mathbf{k P a})$ & $\mathbf{v}\left(\mathbf{m} \cdot \mathbf{s}^{-1}\right)$ \\
\hline 1 & 98 & 0,79 \\
2 & 98 & 1,42 \\
3 & 98 & 2,23 \\
4 & 196 & 0,79 \\
5 & 196 & 1,42 \\
6 & 196 & 2,23 \\
7 & 294 & 0,79 \\
8 & 294 & 1,42 \\
9 & 294 & 2,23 \\
\hline
\end{tabular}

A velocidade tangencial foi estimada a partir da vazão de recirculação - a qual foi medida com o auxílio de cronômetro e proveta - e da área da seção transversal ao escoamento. Para a membrana espiral, o volume total do canal de circulação do retido foi calculado e descontado o volume do espaçador para se obter então a área útil da seção transversal, segundo descrição de Clarke e Heath (1997).

As variáveis de resposta do sistema foram as características do permeado: fluxo permeado, turbidez, DQO, proteínas, lactose, óleos e graxas, cálcio e fósforo. A análise dos dados foi feita por análise de variância (ANOVA) com significância de 5\%, utilizando-se o software Statistica 5.5. Inicialmente, identificou-se qual condição experimental aplicada em cada membrana obteve a maximização do fluxo permeado e a minimização da concentração das demais variáveis de resposta no permeado. Em seguida, confrontou-se a melhor condição experimental selecionada para cada membrana em termos de remoção dos parâmetros analisados.

\subsection{Métodos analíticos}

A turbidez foi medida em espectrofotômetro marca HACH (modelo DR2010). Os ensaios de DQO, fósforo, óleos e graxas, e cálcio seguiram os métodos de American Public Health Association (APHA, 2001). A concentração de proteínas foi mensurada pelo método de Lowri, segundo descrição de Sakai (2002), e a lactose foi medida como um açúcar redutor pelo método do 3,5 DNS (ácido dinitrossalissílico), descrito em Bergamasco (1989).

\subsection{Coeficiente de rejeição}

O coeficiente de rejeição foi calculado de acordo com a Equação 2:

$R=\left(1-\frac{C_{p}}{C_{a}}\right) \times 100$

em que: $\mathrm{R}$ = Coeficiente de Rejeição (\%); $C_{p}=$ concentração do constituinte no permeado $\left(\mathrm{mg} \cdot \mathrm{L}^{-1}\right) ; \mathrm{C}_{\mathrm{a}}=$ concentração do constituinte na alimentação $\left(\mathrm{mg} \cdot \mathrm{L}^{-1}\right)$.

\subsection{Recuperação dos nutrientes por ultrafiltração}

O processo de recuperação dos nutrientes por ultrafiltração foi realizado recirculando o retido no sistema e descartando o permeado. A membrana que apresentou os melhores resultados, em função das variáveis testadas, foi utilizada para a concentração dos nutrientes presentes na água de enxágue. Para tal, partiu-se de um volume de $144 \mathrm{~L}$ de água de enxágue. Este volume foi adicionado no tanque (Figura 1) à medida que o permeado era descartado. A temperatura foi mantida a $23 \pm 1{ }^{\circ} \mathrm{C}$. Calculou-se então o Fator de Concentração (FC) de acordo com a Equação 3, citada por Ballanec et al. (2002).

$\mathrm{FC}=\frac{\mathrm{V}_{0}}{\mathrm{~V}_{\mathrm{r}}}=\frac{\mathrm{V}_{0}}{\mathrm{~V}_{0}-\mathrm{V}_{\mathrm{p}}}$

em que: $V_{o}=$ volume inicial de efluente; $V_{r}=$ volume final de rejeito; $V_{p}=$ volume de permeado.

Observe-se que FC unitário corresponde à alimentação inicial. A água de enxágue foi concentrada até um volume final de 4,2 L, atingindo, deste modo, um FC de 34. Ao longo dos experimentos, amostras de permeado e retido foram coletadas e analisadas, permitindo o acompanhamento das diversas variáveis de resposta em função do FC, as quais foram: sólidos totais, proteínas, óleos e graxas, e lactose.

\section{Resultados e discussão}

\subsection{Caracterização da alimentação}

A Tabela 1 apresenta os resultados da caracterização do efluente modelo que foi utilizado para alimentar o sistema de ultrafiltração. Esses dados foram obtidos pela caracterização de todos os 36 experimentos realizados. A utilização de um efluente modelo minimizou as oscilações da alimentação e manteve a carga orgânica

Tabela 1. Caracterização do efluente modelo alimentado ao processo.

\begin{tabular}{lccccccc} 
& $\begin{array}{c}\text { Turbidez } \\
\text { (FAU) }\end{array}$ & $\begin{array}{c}\text { DQO } \\
\left(\mathbf{m g} \cdot \mathbf{L}^{-1}\right)\end{array}$ & $\begin{array}{c}\text { Proteína } \\
\left(\mathbf{m g} \cdot \mathbf{L}^{-1}\right)\end{array}$ & $\begin{array}{c}\text { Lactose } \\
\left(\mathbf{m g} \cdot \mathbf{L}^{-1}\right)\end{array}$ & $\begin{array}{c}\text { Óleos e graxas } \\
\left(\mathbf{m g} \cdot \mathbf{L}^{-1}\right)\end{array}$ & $\begin{array}{c}\text { Fósforo } \\
\left(\mathbf{m g} \cdot \mathbf{L}^{-1}\right)\end{array}$ & $\begin{array}{c}\text { Cálcio } \\
\left(\mathbf{m g} \cdot \mathbf{L}^{-1}\right)\end{array}$ \\
\hline Média & 2134 & 2241 & 416 & 815 & 611 & 12,1 & 42 \\
Desvio padrão & 60 & 193 & 24 & 15 & 66 & 0,8 & 3 \\
\hline
\end{tabular}


Nota Científica: Ultrafiltração de água de enxágue modelo da indústria de laticínios para a recuperação de nutrientes: efeito da pressão e da velocidade tangencial (ultrafiltração de efluente de laticínios)

BRIÃO, V. B. e TAVARES, C. R. G.

em uma faixa mais estreita. A DQO média da alimentação foi de 2241,1 mg. $\mathrm{L}^{-1}$ e o desvio padrão de 193,7 $\mathrm{mgL}^{-1}$, ou seja, uma variação em torno de $8 \%$.

\subsection{Fluxo permeado e rejeição dos compostos pela membrana tubular}

A Tabela 2 apresenta os valores médios das variáveis de resposta para os ensaios realizados com a membrana tubular em cada condição experimental. As curvas de fluxo estão demonstradas em Brião (2007), e o valor demonstrado é o fluxo estabilizado depois de decorridos 120 minutos de filtração.

Quanto à concentração de óleos e graxas no permeado, verificaram-se quatro diferentes valores estatisticamente diferentes, próximos a duas faixas de concentrações: um primeiro patamar, acima de $100 \mathrm{mg} \cdot \mathrm{L}^{-1}$, e outra faixa, na ordem de $40 \mathrm{mg} \cdot \mathrm{L}^{-1}$, sendo esta segunda observada nas condições de maior velocidade tangencial $\left(2,23 \mathrm{~m} \cdot \mathrm{s}^{-1}\right)$.

A Tabela 3 apresenta a significância (valor p) do efeito das variáveis independentes ( $p$ e v) sobre cada variável de resposta, bem como a interação entre ambas variáveis independentes $(p \times v)$.

Os dados apresentados na Tabela 3 mostraram que a pressão só exerceu efeito sobre a concentração de lactose no permeado. Observou-se também que não houve efeito de interação entre a pressão e a velocidade tangencial para cada variável de resposta estudada. Assim, os dados foram tratados de maneira independente, como afirmam Rodrigues e lemma (2005).

Embora houvesse uma elevação do valor de fluxo com o aumento da pressão, estas diferenças não foram consideradas significativas estatisticamente. 0 aumento da pressão levou a uma maior colmatação da membrana - evidenciada nas últimas colunas das Tabelas 2 e 3 -, elevando a resistência de filtração e, com isso, não foram evidenciados aumentos no fluxo permeado.

O aumento da colmatação acarretou uma maior rejeição de lactose pela membrana, pois esta camada aderida atuava como uma membrana secundária, mesmo que a lactose tivesse uma dimensão menor que os poros da membrana. O efeito da colmatação de membranas de microfiltração na rejeição de Soro Albumina Bovina (SAB) foi estudado por Tracey e Davis (1994), tendo os autores observado que o bloqueio dos poros aumentou a rejeição de BSA, de forma semelhante ao ocorrido neste trabalho com a rejeição da membrana à lactose. Estes resultados diferem dos valores encontrados por Ferez et al. (2008), os quais utilizaram uma membrana de UF com peso molecular de corte de $50 \mathrm{kDa}$ para a recuperação de oligossacarídeos de leite caprino. Os autores identificaram que o aumento de pressão de

Tabela 2. Valores médios das variáveis de resposta frente à variação da pressão e da velocidade tangencial nos ensaios de ultrafiltração realizados com a membrana tubular ${ }^{1}$.

\begin{tabular}{|c|c|c|c|c|c|c|c|c|c|c|}
\hline $\begin{array}{c}\text { Pressão } \\
\text { (kPa) }\end{array}$ & $\begin{array}{c}\text { Velocidade } \\
\text { tangencial } \\
\left(\mathrm{m} \cdot \mathrm{s}^{-1}\right)\end{array}$ & $\begin{array}{c}\text { Fluxo } \\
\text { permeado } \\
\left(\mathbf{k g} \cdot \mathrm{m}^{-2} \cdot \mathbf{h}^{-1}\right)\end{array}$ & $\begin{array}{c}\text { Turbidez } \\
\text { FAU }\end{array}$ & $\begin{array}{c}\text { DQO } \\
\left(\mathrm{mg} \cdot \mathrm{L}^{-1}\right)\end{array}$ & $\begin{array}{l}\text { Proteína } \\
\left(\mathrm{mg} \cdot \mathrm{L}^{-1}\right)\end{array}$ & $\begin{array}{l}\text { Lactose } \\
\left.\text { (mg. } \mathrm{L}^{-1}\right)\end{array}$ & $\begin{array}{l}\text { Óleos e } \\
\text { graxas } \\
\left(\mathrm{mg} \cdot \mathrm{L}^{-1}\right)\end{array}$ & $\begin{array}{l}\text { Fósforo } \\
\left(\mathrm{mg} \cdot \mathrm{L}^{-1}\right)\end{array}$ & $\begin{array}{l}\text { Cálcio } \\
\text { (mg.L-1) }\end{array}$ & $\begin{array}{c}\text { Coeficiente } \\
\text { Colmatação } \\
\text { Adimensional }\end{array}$ \\
\hline 98 & 0,79 & $27,1^{\mathrm{a}}$ & $0,5^{a}$ & $676^{a}$ & $17^{a}$ & $609^{a}$ & $145^{a}$ & $5,9^{a}$ & $22^{a}$ & $0,85^{a, b}$ \\
\hline 196 & 0,79 & $23,1^{a, b}$ & $0,5^{a}$ & $626^{(a}$ & $12^{\mathrm{a}}$ & $595^{a, b}$ & $133^{a, b, c}$ & $5,9^{a}$ & $21^{a}$ & $0,88^{b, c}$ \\
\hline 294 & 0,79 & $21,7^{a, b}$ & $0,5^{a}$ & $658^{a}$ & $g^{a}$ & $562^{b}$ & $137^{a, b}$ & $5,5^{\mathrm{a}}$ & $21^{a}$ & $0,92^{c}$ \\
\hline 98 & 1,42 & $42,2^{b, c}$ & $0,5^{a}$ & $607^{a}$ & $13^{a}$ & $611^{a}$ & $111^{\mathrm{b}, \mathrm{c}}$ & $6,4^{a}$ & $21^{a}$ & $0,85^{b}$ \\
\hline 196 & 1,42 & $45,6^{a, b, c}$ & $0,5^{a}$ & $642^{a}$ & $15^{\mathrm{a}}$ & $586^{a, b}$ & $105^{c}$ & $6,9^{a}$ & $23^{a}$ & $0,91^{b, c}$ \\
\hline 294 & 1,42 & $51,9^{c}$ & $0,0^{a}$ & $584^{a}$ & $13^{a}$ & $560^{b}$ & $119^{a, b, c}$ & $5,5^{a}$ & $21^{a}$ & $0,92^{c}$ \\
\hline 98 & 2,23 & $76,7^{d}$ & $0,5^{a}$ & $636^{a}$ & $11^{\mathrm{a}}$ & $606^{a}$ & $42^{d}$ & $6,5^{\mathrm{a}}$ & $21^{a}$ & $0,82^{a}$ \\
\hline 196 & 2,23 & $83,0^{d}$ & $0,0^{a}$ & $634^{a}$ & $11^{a}$ & $595^{a, b}$ & $44^{d}$ & $6,1^{\mathrm{a}}$ & $20^{a}$ & $0,89^{b, c}$ \\
\hline 294 & 2,23 & $93,2^{d}$ & $0,5^{a}$ & $641^{a}$ & $12^{\mathrm{a}}$ & $576^{a, b}$ & $39^{d}$ & $6,1^{a}$ & $19^{a}$ & $0,91^{b, c}$ \\
\hline
\end{tabular}

${ }^{1}$ Em uma mesma coluna, índices iguais representam iguais valores encontrados pela comparação estatística de médias. DQO Demanda Química de Oxigênio.

Tabela 3. Significância (valor $p$ ) do efeito da pressão ( $p$ ), velocidade tangencial ( $v$ ) e interação de ambos os fatores ( $p \times v)$ nas variáveis de resposta nos ensaios de ultrafiltração realizados com a membrana tubular ${ }^{1}$.

\begin{tabular}{lcccccccccc} 
& Fluxo & Turbidez & DQO & Proteína & Lactose & $\begin{array}{c}\text { Óleos e } \\
\text { graxas }\end{array}$ & Fósforo & $\begin{array}{c}\text { Cálcio } \\
\text { Coeficiente } \\
\text { Colmatação }\end{array}$ \\
\hline p & 0,739 & 0,869 & 0,929 & 0,250 & 0,000 & 0,418 & 0,155 & 0,806 & 0,000 \\
V & 0,000 & 0,869 & 0,819 & 0,279 & 0,605 & 0,000 & 0,328 & 0,697 & 0,093 \\
p $\times v$ & 0,794 & 0,833 & 0,978 & 0,116 & 0,602 & 0,301 & 0,558 & 0,942 & 0,609 \\
\hline
\end{tabular}

${ }^{1}$ Valores de $p$ menores que 0,05 são considerados significativos. DQO Demanda Química de Oxigênio. 
Nota Científica: Ultrafiltração de água de enxágue modelo da indústria de laticínios para a recuperação de nutrientes: efeito da pressão e da velocidade tangencial (ultrafiltração de efluente de laticínios)

BRIÃO, V. B. e TAVARES, C. R. G.

100 kPa para 150 kPa não aumentou a rejeição de lactose através da membrana. Contudo, os autores não realizaram a medida do coeficiente de colmatação, não havendo a certeza de que a membrana encontrava-se com um maior bloqueio de poros na condição de maior pressão.

A maior colmatação da membrana justifica também a estabilidade do fluxo frente ao aumento da força motriz do processo (pressão transmembrana), pois embora se possam obter maiores fluxos iniciais, pode haver um aumento maior da resistência ao fluxo em função da compressão desta camada aderida à membrana.

Os níveis testados de velocidade tangencial não exerceram efeito sobre os constituintes analisados do permeado. Observou-se que o aumento de velocidade tangencial não conduziu a menores concentrações de DQO, proteína, lactose, fósforo e cálcio no permeado. Ferreira (2001) estudou a concentração de caseína por microfiltração e não encontrou diferenças na rejeição da membrana a proteínas quando variadas a pressão e a velocidade tangencial.

Foram constatadas diferenças estatísticas na concentração de óleos e graxas presentes no permeado, sendo que a menor concentração deste parâmetro foi obtida com a maior velocidade tangencial (aproximadamente a metade do valor dos outros níveis testados da variável independente). Segundo James et al. (2003), os glóbulos de gordura do leite são maiores que $500 \mathrm{~nm}$, sendo retidos por membranas de ultrafiltração e concentrados junto com as proteínas na fração do retentado. Contudo, as membranas possuem uma densidade de poros com tamanhos diferentes, havendo a passagem de gordura através da membrana. 0 aumento da velocidade tangencial reduz a polarização de concentração próxima à membrana e, com isso, reduz-se o efeito da transferência de massa através da mesma.

O efeito da velocidade tangencial no fluxo permeado está associado ao aumento da turbulência, reduzindo a espessura da camada polarizada (LIN et al., 2004). Além disso, a velocidade tangencial aumenta a taxa de cisalhamento próxima à membrana e, consequentemente, há uma redução do depósito de partículas (moléculas ou coloides) e da retrodifusão dos compostos que são conduzidos até a membrana, responsáveis pela redução de fluxo (DRIOLI et al., 2003).

A melhor condição experimental de velocidade tangencial foi de 2,23 m. $\mathrm{s}^{-1}$, reduzindo a concentração de óleos e graxas, e obtendo-se um maior fluxo permeado, enquanto que a pressão de 294 kPa apresentou uma menor concentração de lactose no permeado. Estas duas condições foram selecionadas como melhor condição experimental da membrana tubular para ser confrontada com a membrana espiral.

\subsection{Fluxo permeado e rejeição dos compostos pela membrana espiral}

A Tabela 4 apresenta os valores médios de cada variável de resposta obtida para cada condição experimental testada, nos ensaios realizados com a membrana de ultrafiltração de configuração espiral. A turbidez do permeado foi próxima de zero em todas as condições experimentais testadas, bem como não foram encontradas diferenças significativas para as concentrações de DQO, proteína, óleos e graxas, fósforo e cálcio do permeado. Quanto ao fluxo permeado, duas condições produziram o seu maior valor: com as pressões de 196 kPa e $294 \mathrm{kPa}$, e quando utilizada a velocidade tangencial de 0,44 m. $\mathrm{s}^{-1}$, obtendo-se um fluxo permeado maior que $30 \mathrm{~kg} \cdot \mathrm{m}^{-2} \cdot \mathrm{h}^{-1}$. Quanto à colmatação da membrana, observaram-se diferenças significativas entre as condições experimentais testadas.

A Tabela 5 apresenta a significância (valor p) do efeito da pressão ( $p$ ) e da velocidade tangencial ( $v$ ) sobre cada variável de resposta, bem como a interação entre ambas variáveis independentes $(p \times v)$.

Tabela 4. Valores médios das variáveis de resposta nas diferentes condições de pressão e velocidade tangencial nos ensaios de ultrafiltração realizados com a membrana espiral ${ }^{1}$.

\begin{tabular}{|c|c|c|c|c|c|c|c|c|c|c|}
\hline $\begin{array}{c}\text { Pressão } \\
\text { (kPa) }\end{array}$ & $\begin{array}{c}\text { Velocidade } \\
\text { tangencial } \\
\left(\mathrm{m} . \mathrm{s}^{-1}\right)\end{array}$ & $\begin{array}{c}\text { Fluxo } \\
\left(\mathrm{kg} \cdot \mathrm{m}^{-2} \cdot \mathrm{h}^{-1}\right)\end{array}$ & $\begin{array}{c}\text { Turbidez } \\
\text { FAU }\end{array}$ & $\begin{array}{c}\text { DQO } \\
\left(\mathrm{mg} \cdot \mathrm{L}^{-1}\right)\end{array}$ & $\begin{array}{l}\text { Proteína } \\
\left(\mathrm{mg} \cdot \mathrm{L}^{-1}\right)\end{array}$ & $\begin{array}{l}\text { Lactose } \\
\left(\mathrm{mg} \cdot \mathrm{L}^{-1}\right)\end{array}$ & $\begin{array}{l}\text { Óleos e } \\
\text { graxas } \\
\left(\mathrm{mg} \cdot \mathrm{L}^{-1}\right)\end{array}$ & $\begin{array}{l}\text { Fósforo } \\
\left(\mathrm{mg} \cdot \mathrm{L}^{-1}\right)\end{array}$ & $\begin{array}{l}\text { Cálcio } \\
\text { (mg.L-1) }\end{array}$ & $\begin{array}{l}\text { Coeficiente } \\
\text { Colmatação } \\
\text { Adimensional }\end{array}$ \\
\hline 98 & 0,15 & $18,1^{a}$ & $0,0^{a}$ & $616^{a}$ & $8^{a}$ & $612^{a}$ & $21,0^{a}$ & $7,3^{a}$ & $26^{a}$ & $0,72^{a, b}$ \\
\hline 196 & 0,15 & $25,6^{b}$ & $0,5^{a}$ & $625^{a}$ & $8^{a}$ & $617^{a}$ & $32^{a}$ & $6,7^{a}$ & $26^{a}$ & $0,77^{\mathrm{b}, \mathrm{c}, \mathrm{d}, \mathrm{e}}$ \\
\hline 294 & 0,15 & $27,9^{b, c}$ & $0,5^{a}$ & $609^{a}$ & $7^{a}$ & $582^{a}$ & $24^{a}$ & $6,8^{a}$ & $27^{a}$ & $0,80^{d, e}$ \\
\hline 98 & 0,27 & $17,6^{a}$ & $0,5^{a}$ & $627^{a}$ & $7^{a}$ & $633^{a}$ & $26^{a}$ & $7,2^{a}$ & $27^{a}$ & $0,71^{a}$ \\
\hline 196 & 0,27 & $26,6^{b, c}$ & $0,5^{a}$ & $631^{a}$ & $8^{a}$ & $623^{a}$ & $29^{a}$ & $7,1^{\mathrm{a}}$ & $28^{a}$ & $0,75^{a, b, c, d}$ \\
\hline 294 & 0,27 & $30,2^{c}$ & $0,5^{a}$ & $625^{a}$ & $8^{a}$ & $601^{a}$ & $21^{a}$ & $7,0^{\mathrm{a}}$ & $27^{a}$ & $0,82^{\mathrm{e}}$ \\
\hline 98 & 0,44 & $18,1^{a}$ & $0,0^{a}$ & $613^{a}$ & $8^{a}$ & $642^{a}$ & $28^{a}$ & $7,1^{\mathrm{a}}$ & $27^{a}$ & $0,72^{a, b}$ \\
\hline 196 & 0,44 & $30,9^{c, d}$ & $0,0^{a}$ & $613^{a}$ & $8^{a}$ & $629^{a}$ & $34^{a}$ & $7,3^{\mathrm{a}}$ & $27^{a}$ & $0,73^{a, b, c}$ \\
\hline 294 & 0,44 & $34,8^{d}$ & $0,5^{\mathrm{a}}$ & $612^{a}$ & $8^{a}$ & $612^{a}$ & $24^{a}$ & $7,3^{\mathrm{a}}$ & $28^{a}$ & $0,78^{\mathrm{c}, \mathrm{d}, \mathrm{e}}$ \\
\hline
\end{tabular}

${ }^{1}$ Em uma mesma coluna, índices iguais representam iguais valores encontrados pela comparação estatística de médias. DQO Demanda Química de Oxigênio. 
Nota Científica: Ultrafiltração de água de enxágue modelo da indústria de laticínios para a recuperação de nutrientes: efeito da pressão e da velocidade tangencial (ultrafiltração de efluente de laticínios)

BRIÃO, V. B. e TAVARES, C. R. G.

As diferentes pressões testadas não promoveram variações nos valores de turbidez, DQO, proteína, óleos e graxas, fósforo e cálcio no permeado. Portanto, não houve diferenças entre os valores médios encontrados entre estes parâmetros nos três níveis de pressão testados. A DQO do permeado oscilou em um patamar próximo de 600 mg. L ${ }^{-1}$, não demonstrando tendências relacionadas à pressão aplicada. A concentração de proteínas manteve-se próxima de $8 \mathrm{mg} \cdot \mathrm{L}^{-1}$ e a concentração de óleos e graxas, em torno de $30 \mathrm{mg} . \mathrm{L}^{-1}$. Por outro lado, a pressão exerceu efeito sobre o fluxo permeado e sobre a colmatação da membrana.

Foi observado que os níveis aplicados de velocidade tangencial não apresentaram efeito sobre as variáveis de resposta, não havendo diferenças significativas entre os valores de fluxo, turbidez, DQO, proteína, lactose, óleos e graxas, fósforo e cálcio. Por outro lado, a velocidade tangencial demonstrou influenciar o fluxo permeado, de modo semelhante ao ocorrido na membrana tubular.

A pressão e a velocidade tangencial apresentaram um efeito combinado sobre o fluxo permeado, havendo a interação entre elas $(p=0,020)$, apresentada na última linha da Tabela 5. A interação entre pressão e velocidade tangencial também foi identificada no trabalho de Clarke e Heath (1997), os quais ultrafiltraram leite desnatado em uma membrana de configuração espiral e peso molecular de corte de 50 kDa. Os autores identificaram a dependência do fluxo permeado com ambos os fatores (pressão e velocidade tangencial) e, utilizando pressão de $224 \mathrm{kPa}$ e velocidade tangencial de 0,3 m.s $\mathrm{s}^{-1}$, obtiveram fluxo permeado de cerca de $13 \mathrm{~L} . \mathrm{m}^{-2} \cdot \mathrm{h}^{-1}$ (valor menor que $\left.30 \mathrm{~kg} \cdot \mathrm{m}^{-2} \cdot \mathrm{h}^{-1}\right)$, um efeito direto da maior concentração do leite desnatado em relação à água de enxágue, o que aumenta o efeito de polarização de concentração.

Turan (2004) estudou diferentes pressões e velocidades tangenciais em membranas de nanofiltração e osmose inversa para a filtração de efluente de laticínios, identificando também que, em pressões menores, não havia o efeito da velocidade tangencial, enquanto que, para maiores valores de pressões, havia maior influência da velocidade tangencial, elevando o fluxo permeado.
O maior fluxo permeado foi obtido com a velocidade tangencial de 0,44 m.s $\mathrm{s}^{-1}$ e com pressões de $196 \mathrm{kPa}$ e $294 \mathrm{kPa}$, obtendo-se fluxos permeados de $30,9 \mathrm{~kg} \cdot \mathrm{m}^{-2} \cdot \mathrm{h}^{-1}$ e $34,8 \mathrm{~kg} \cdot \mathrm{m}^{-2} \cdot \mathrm{h}^{-1}$, sendo estes considerados iguais estatisticamente. Na medida em que as outras condições experimentais não apresentaram efeito nas demais variáveis de resposta, selecionaram-se os resultados obtidos com a condição experimental de pressão de $294 \mathrm{kPa}$ e de velocidade tangencial de 0,44 m.s ${ }^{-1}$ para comparação com a membrana tubular.

\subsection{Comparação entre o desempenho das membranas espiral e tubular}

Depois de obtida a melhor condição de operação para as membranas tubular e espiral, foi possível realizar uma comparação entre o desempenho das mesmas, de modo a selecionar a membrana que melhor se adaptaria à aplicação proposta.

A Tabela 6 apresenta o fluxo permeado e as demais variáveis de resposta obtidas na condição ótima selecionada para cada membrana, além das remoções obtidas.

Os valores de turbidez, DQO, proteína e fósforo dos permeados, obtidos com as membranas espiral e tubular, não apresentaram diferenças significativas. A membrana tubular apresentou um maior fluxo (cerca de 250\% maior) e uma menor concentração de cálcio e lactose, embora estes últimos valores encontrem-se dentro de uma pequena faixa. A membrana espiral obteve um permeado com uma menor concentração de óleos e graxas (42\% menor).

A Tabela 6 mostra que não houve uma membrana que apresentasse vantagens em termos de todas as variáveis de resposta. De um modo geral, ambas as membranas apresentaram uma remoção de matéria orgânica (DQO) acima de 70\%, removendo proteínas acima de 94\% e gorduras acima de 85\%. Quanto à lactose, a camada depositada sobre a superfície da membrana auxilia nesta retenção, chegando-se à remoção na faixa de $25 \%$ a $30 \%$. Em razão da maior remoção de gordura pela membrana espiral, esta foi selecionada para realizar a concentração da água de enxágue de laticínios.

Tabela 5. Significância (valor p) do efeito da pressão ( $p$ ), da velocidade tangencial ( $v$ ) e da interação de ambas ( $p \times v$ ) nas variáveis de resposta, nos ensaios de ultrafiltração realizados com a membrana espiral ${ }^{1}$.

\begin{tabular}{lcccccccccc} 
& $\begin{array}{c}\text { Fluxo } \\
\text { permeado }\end{array}$ & Turbidez & DQO & Proteína & Lactose & $\begin{array}{c}\text { Óleos e } \\
\text { graxas }\end{array}$ & Fósforo & $\begin{array}{c}\text { Coeficiente } \\
\text { Cálcio } \\
\text { Colmatação }\end{array}$ \\
\hline $\mathrm{p}$ & 0,000 & 0,622 & 0,890 & 0,615 & 0,058 & 0,081 & 0,931 & 0,933 & 0,000 \\
$\mathrm{~V}$ & 0,000 & 0,622 & 0,635 & 0,246 & 0,170 & 0,577 & 0,767 & 0,319 & 0,103 \\
$\mathrm{p} \times \mathrm{V}$ & 0,020 & 0,902 & 0,996 & 0,316 & 0,960 & 0,835 & 0,932 & 0,947 & 0,243 \\
\hline
\end{tabular}

${ }^{1}$ Valores menores que 0,05 são considerados significantes. DQO Demanda Química de Oxigênio. 
Nota Científica: Ultrafiltração de água de enxágue modelo da indústria de laticínios para a recuperação de nutrientes: efeito da pressão e da velocidade tangencial (ultrafiltração de efluente de laticínios)

BRIÃO, V. B. e TAVARES, C. R. G.

\subsection{Concentração dos nutrientes presentes na água de enxágue por ultrafiltração}

A Figura 2 mostra o comportamento do permeado e do retido no decorrer da concentração dos nutrientes presentes na água de enxágue por ultrafiltração. À medida que a água de enxágue é concentrada, há uma maior permeação através da membrana pelos nutrientes e, ao final do processo, quando atingido o $\mathrm{FC}$ de 34 , o retido continha uma maior concentração de proteínas (11704 mg. L-1) do que óleos e graxas (9122 mg..-1), em função de maior rejeição de proteínas pela membrana (evidenciada na última coluna da Tabela 6) em relação à rejeição de óleos e gorduras durante todo o processo.
O retido final apresentou uma parcela menor de lactose (2458 mg.L-1) por causa da maior permeação desta e a concentração de sólidos totais foi de $23148 \mathrm{mg} \cdot \mathrm{L}^{-1}$ (cerca de 2,3\%), elevando esta concentração em cerca de treze vezes.

Esta elevação do teor de sólidos totais do retido mostra que a ultrafiltração pode ser aplicada como um processo in plant para recuperação de nutrientes. $O$ permeado final ainda apresenta uma concentração de $1284 \mathrm{mg} . \mathrm{L}^{-1}$ de sólidos totais, resultando uma DQO de 977 mg. L $^{-1}$ (não apresentada na Figura 2). Contudo, houve uma redução de DQO superior a 70\% (Tabela 6), o que indica que menores custos seriam necessários para o tratamento desta corrente antes de descartá-la aos

Tabela 6. Comparação entre o desempenho das melhores condições experimentais obtidas com as membranas tubular (pressão de $294 \mathrm{kPa}$ e velocidade tangencial de 2,23 m.s. $\mathrm{s}^{-1}$ ) e espiral (pressão de $294 \mathrm{kPa}$ e velocidade tangencial de 0,44 m.s ${ }^{-1}$ ), na ultrafiltração do efluente modelo de laticínios.

\begin{tabular}{|c|c|c|c|c|}
\hline \multirow{2}{*}{ Variável de resposta ${ }^{1}$} & \multicolumn{2}{|c|}{ Concentração no permeado } & \multicolumn{2}{|c|}{ Remoção (\%) } \\
\hline & Membrana tubular & Membrana espiral & Tubular & Espiral \\
\hline Fluxo $\left(\mathrm{kg} \cdot \mathrm{m}^{-2} \cdot \mathrm{h}^{-1}\right)$ & $93,17^{a}$ & $34,78^{b}$ & - & - \\
\hline Turbidez (FAU) & $0,5^{a}$ & $0,5^{a}$ & $99,98^{c}$ & $99,98^{c}$ \\
\hline $\mathrm{DQO}\left(\mathrm{mg} \cdot \mathrm{L}^{-1}\right)$ & $641,0^{a}$ & $612,5^{a}$ & $71,31^{c}$ & $72,47^{\circ}$ \\
\hline Proteína (mg. $\mathrm{L}^{-1}$ ) & $12,4^{\mathrm{a}}$ & $8,0^{a}$ & $96,98^{\circ}$ & $98,04^{c}$ \\
\hline Lactose $\left(\mathrm{mg} \cdot \mathrm{L}^{-1}\right)$ & $575,9^{a}$ & $612,0^{b}$ & $29,97^{c}$ & $24,89^{\circ}$ \\
\hline Óleos e graxas (mg. L-1) & $73,5^{a}$ & $31,5^{b}$ & $85,13^{c}$ & $94,79^{d}$ \\
\hline Fósforo (mg.L-1) & $6,1^{\mathrm{a}}$ & $7,3^{\mathrm{a}}$ & $55,13^{c}$ & $38,85^{c}$ \\
\hline Cálcio $\left(\mathrm{mg} \cdot \mathrm{L}^{-1}\right)$ & $19,1^{\mathrm{a}}$ & $27,7^{b}$ & $52,45^{c}$ & $33,71^{\mathrm{d}}$ \\
\hline
\end{tabular}

${ }^{1}$ Em uma mesma linha, índices iguais representam valores estatisticamente iguais.

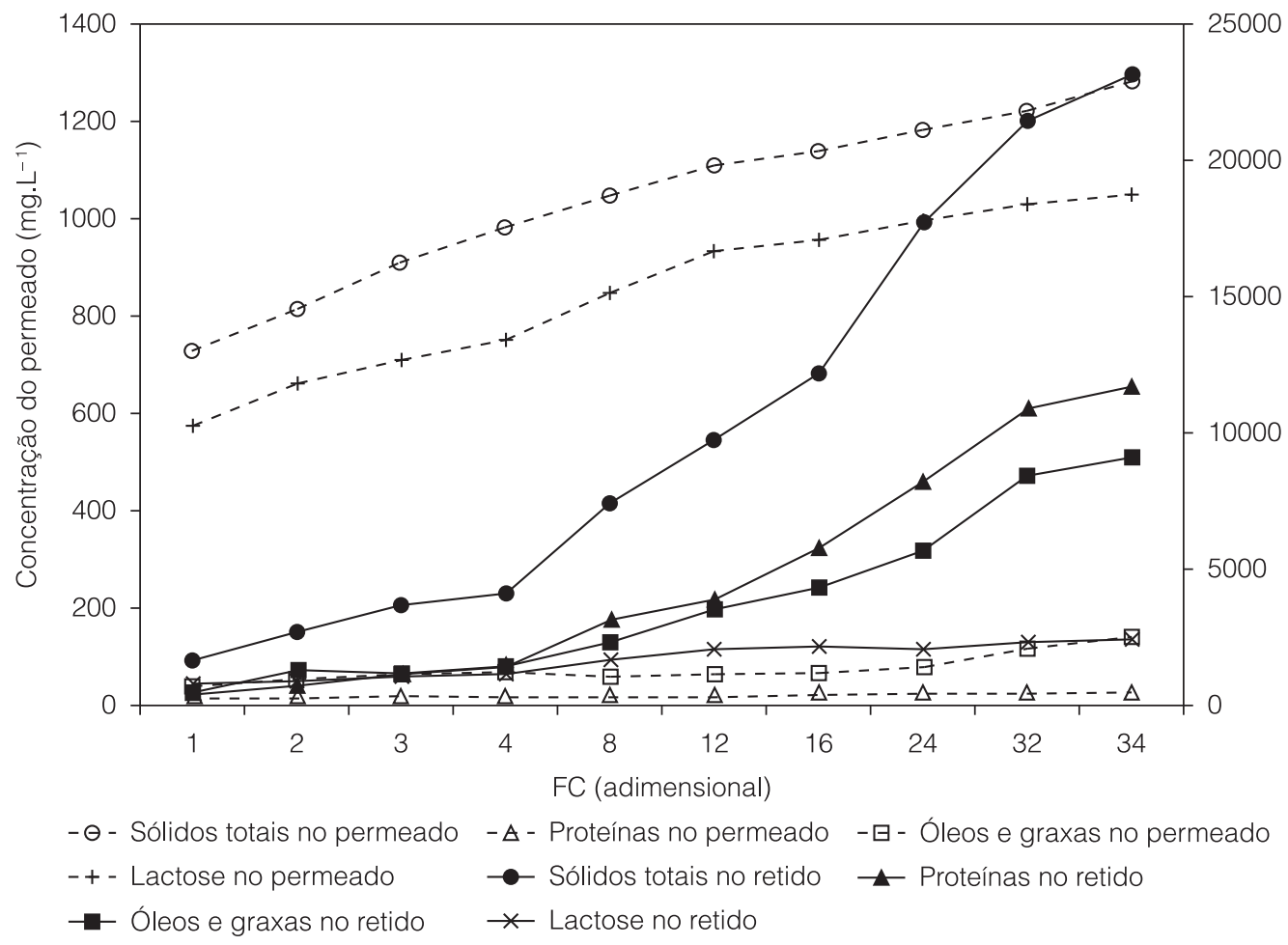

25000

20000

Figura 2. Concentrações de sólidos totais, proteínas, óleos e graxas, e lactose no decorrer da recuperação dos nutrientes presentes na água de enxágue de laticínios com a membrana espiral de ultrafiltração. 
Nota Científica: Ultrafiltração de água de enxágue modelo da indústria de laticínios para a recuperação de nutrientes: efeito da pressão e da velocidade tangencial (ultrafiltração de efluente de laticínios)

BRIÃO, V. B. e TAVARES, C. R. G.

corpos receptores. A concentração de águas residuárias de laticínios foi realizada também por Ballanec et al. (2002) e Akoum et al. (2004) em membranas de nanofiltração e osmose inversa, e o aumento da DQO do permeado também foi observado à medida que aumentava a concentração; note-se que, mesmo utilizando membranas com maiores rejeições aos constituintes presentes no efluente, a DQO do permeado evoluiu até $840 \mathrm{mg} \cdot \mathrm{L}^{-1}$.

A recuperação (relação entre a massa final no retido e a massa inicial presente na água de enxágue) foi de $82 \%$ de proteínas, $43 \%$ de óleos e graxas, e $8,8 \%$ de lactose. Este concentrado lácteo obtido por ultrafiltração tem possibilidades de retornar ao processo de produção, sendo adicionado para a elaboração de produtos como doce de leite, composto lácteo ou bebida láctea, os quais permitem essa adição de sólidos lácteos em suas formulações. O maior teor de proteínas em relação aos demais nutrientes também permite que, se o concentrado for desidratado, o mesmo seja uma opção de insumo para o enriquecimento de outros alimentos que possuam baixo teor proteico. Por fim, além do consumo humano, outras possibilidades poderiam ser exploradas, de forma semelhante ao soro de leite em pó, empregado como insumo para ração animal.

\section{Conclusões}

Para o processo de ultrafiltração das águas de enxágue de laticínios com a membrana tubular, a operação do sistema com maiores velocidades tangenciais proporcionou a elevação do fluxo permeado e a redução da concentração de óleos e graxas no permeado, enquanto que a elevação da pressão promoveu a redução da concentração de lactose no permeado, embora dentro de uma pequena faixa. Quanto utilizada a membrana espiral, os diferentes valores de pressão e velocidade tangencial não produziram diferenças na qualidade do permeado, embora ambas as variáveis tenham promovido efeito positivo no fluxo permeado.

Ambas as membranas apresentaram desempenho semelhante para a recuperação de nutrientes da água de enxágue de laticínios, removendo cerca de $70 \%$ da DQO, aproximadamente $97 \%$ de proteínas e acima de $85 \%$ de gorduras.

A concentração do efluente por ultrafiltração permitiu a obtenção de um retido com 2,3\% de sólidos totais, $1,1 \%$ de proteínas, $0,9 \%$ de gorduras e $0,25 \%$ de lactose. Em termos de valores mássicos, a recuperação foi de $83 \%$ de proteínas, $43 \%$ de gorduras e $8,8 \%$ de lactose, mostrando a possibilidade técnica de recuperar nutrientes da água de enxágue de laticínios por ultrafiltração.

\section{Referências}

AMERICAN PUBLIC HEALTH ASSOCIATION - APHA. Standard Methods for the Examination of Water and Wastewater. 19th ed. Washington: APHA, 2001. $1289 \mathrm{p}$.
AKOUM, O.; JAFFRIN, M. Y.; DING, L. H.; FRAPPART, M. Treatment of dairy process water using a vibrating filtration system and NF and RO membranes. Journal of Membrane Science, Amsterdan, v. 235, n. 1-2, p. 111-122, 2004. http:// dx.doi.org/10.1016/j.memsci.2004.01.026

BERGAMASCO, R. Cinética da Hidrólise da Sacarose pela Invertase: Modelagem Matemática. 1989. 89 f. Dissertação (Mestrado em Ciência de Alimentos)-Universidade Estadual de Londrina, Londrina, 1989.

BALLANEC, B.; GÉSAN-GUIZIOU, G.; CHAUFER, B.; RABILLERBAUDRY, M.; DAUFIN, G. Treatment of dairy process waters by membrane operation for water reuse and milk constituents concentration. Desalination, Amsterdan, v. 147, n. 1-3, p. 89-94, 2002. http://dx.doi.org/10.1016/S00119164(02)00581-7

BALANNEC, B.; VOURCH, M.; RABILLER-BAUDRY, M.; CHAUFER, B. Comparative study of different nanofiltration and reverse osmosis membranes for dairy effluent treatment by dead-end filtration. Separation Purification Technology, Amsterdan, v. 42, n. 2, p. 195-205, 2005. http://dx.doi. org/10.1016/j.seppur.2004.07.013

BASKARAN, K.; PALMOWSKI, L. M.; WATSON, B. M. Wastewater reuse and treatment options for the dairy industry. Water Science \& Technology: Water Supply, London, v. 3, n. 3, p. 85-91, 2003.

BRASIL. Lei Federal n 9433/97, de 8 de janeiro de 1997. Institui a Política Nacional de Recursos Hídricos, cria o Sistema Nacional de Gerenciamento de Recursos Hídricos. Diário Oficial da República Federativa do Brasil, Brasília, DF, 09 jan. 1997. 15 p.

BRIÃO, V. B. Processos de Separação por Membranas para Reuso de Efluentes de Laticínios. 2007. 163 f. Doutorado (Tese de Doutorado em Engenharia Química)-Universidade Estadual de Maringá, Maringá, 2007.

BRIÃO, V. B.; TAVARES, C. R. G. Effluent generation by the dairy industry: preventive attitudes and opportunities. Brazilian Journal of Chemical Engineering, São Paulo, v. 24, n. 4, p. 487-497, 2007. http://dx.doi.org/10.1590/S010466322007000400003

CHMIEL, H.; MAVROV, V.; BÉLIÈRES, E. Reuse of vapour condensate from milk processing using nanofiltration. Filtration and Separation, Amsterdan, v. 37, n. 3, p. 24-27, 2000. http:// dx.doi.org/10.1016/S0015-1882(00)88493-1

CLARKE, T. E.; HEATH, C. A. Ultrafiltration of skim milk in flatplate and spiral-wound modules. Journal of Food Engineering, Amsterdan, v. 33, n. 3-4, p. 373-383, 1997. http://dx.doi. org/10.1016/S0260-8774(97)00057-5

DRIOLI, C. E.; GALAVERNA, G.; MARCHELLI, R.; SILVESTO, G.; CAGNASSO, P. Clarification and concentration of citrus and carrot juices by integrated membrane processes. Journal of 
Nota Científica: Ultrafiltração de água de enxágue modelo da indústria de laticínios para a recuperação de nutrientes: efeito da pressão e da velocidade tangencial (ultrafiltração de efluente de laticínios)

BRIÃO, V. B. e TAVARES, C. R. G.

Food Engineering, Amsterdan, v. 57, n. 2, p. 153-163, 2003. http://dx.doi.org/10.1016/S0260-8774(02)00293-5

DYRSET, N.; SELMER-OLSEN, E.; HAVREVOLL, O.; RATNAWEERA, H.; STORRO, I.; BIRKELAND, S. E. Feed supplement recovered from dairy wastewater by biological and chemical pretreatment. Journal of Chemical Technology and Biotechnology, Oxford, v. 73, n. 3, p. 175-182, 1998. http:// dx.doi.org/10.1002/(SICI)1097-4660(1998110)73:3<175::AIDJCTB936>3.0.CO;2-0

INSTITUTO BRASILEIRO DE GEOGRAFIA E ESTATÍSTICA - IBGE. Produção Brasileira de Leite. IBGE, 2010. Relatório Anual de Produção Agropecuária. Disponível em: <http://www. cnpgl.embrapa.br/nova/informacoes/estatisticas/producao/ tabela0231.php>. Acesso em: 02 ago. 2012.

FEREZ, A. M.; GUADIX, A.; MONTOYA, J. E. Z.; GUADIX, E. $M$. Influence of transmembrane pressure on the separation of caprine milk oligosaccharides from protein by cross-flow ultrafiltration. International Journal of Dairy Technology, Oxford, v. 61, n. 4, p. 333-339, 2008. http://dx.doi.org/10.1111/ j.1471-0307.2008.00434.x

FERREIRA, C. V. Influencia da Velocidade Tangencial e da Pressão Transmembrana na Obtenção de Caseina por Microfiltração. 2001. 89 f. Dissertação (Mestrado em Engenharia de Alimentos)-Faculdade de Engenharia de Alimentos, Universidade Estadual de Campinas, Campinas, 2001.

JAMES, B. J.; JYNG, Y.; CHENG, X. D. Membrane Fouling during filtration of milk - a microstructural study. Journal of Food Engineering, Amsterdan, v. 60, n. 4, p. 431-437, 2003. http:// dx.doi.org/10.1016/S0260-8774(03)00066-9

KOYUNCU, I.; TURAN, M.; TOPACIK, D.; ATES, A. Application of low pressure nanofiltration membranes for the recovery and reuse of dairy industry effluents. Water Science and Technology, London, v. 41, n. 1, p. 213-221, 2000.

LIN, C.-J.; RAO, P.; SHIRAZI, S. Effect of operating parameters on permeate flux decline caused by cake formation - a model study. Desalination, Amsterdan, v. 171, n. 1, p. 95-105, 2004. http://dx.doi.org/10.1016/j.desal.2004.03.023

MAVROV, V.; CHMIEL, H.; BÉLIÈRES, E. Spent process water desalination and organic removal by membranes for water reuse in the food industry. Desalination, Amsterdan, v. 138, n. 1-3, p. 65-74, 2001. http://dx.doi.org/10.1016/S00119164(01)00246-6

PEPPIN, S. L.; ELLIOT, J. A. W. Non-equilibrium thermodynamics of concentration polarization. Advances in Colloid and Interface Science, Amsterdan, v. 92, n. 1-3, p. 1-72, 2001. http:// dx.doi.org/10.1016/S0001-8686(00)00029-4

RAO, R. H. G. Mechanisms of flux decline during ultrafiltration of dairy products and influence of $\mathrm{pH}$ on flux rates of whey and buttermilk. Desalination, Amsterdan, v. 144, n. 1-3, p. 319-324, 2002. http://dx.doi.org/10.1016/S00119164(02)00336-3

RODRIGUES, M. I.; IEMMA, A.F. Planejamento e Otimização de Experimentos. Campinas: Casa do Pão Editora, 2005. 618 p.

SAKAI, C. R. Pré-tratamento de Soro de Queijo para Obtenção de Concentrado Protéico por Ultrafiltração. 2002. 102 f. Dissertação (Mestrado em Engenharia Química)-Universidade Federal de Uberlândia, Uberlândia, 2002.

SARKAR, B.; CHAKRABARTI, P. P.; VIJAYKUMAR, V.; KALE, V. Wastewater treatment in dairy industries - possibility of reuse, Desalination, Amsterdan, v. 195, n. 1-3, p. 141-152, 2006. http:// dx.doi.org/10.1016/j.desal.2005.11.015

TRACEY, E. M.; DAVIS, R. H. Protein fouling of tracketched polycarbonate microfiltration membranes. Journal of Colloid and Interface Science, Amsterdan, v. 167, n. 1, p. 104-116, 1994. http://dx.doi.org/10.1006/jcis.1994.1338

TURAN, M. Influence of filtration conditions on the performance of nanofiltration and reverse osmosis membranes in dairy wastewater treatment. Desalination, Amsterdan, v. 170, n. 1, p. 83-90, 2004. http://dx.doi.org/10.1016/j.desal.2004.02.094

VOURCH, M.; BALANNEC, B.; CHAUFER, B.; DORANGE, G. Nanofiltration and reverse osmosis of model process waters from the dairy industry to produce water for reuse. Desalination, Amsterdan, v.172, n. 3, p. 245-256, 2005. http://dx.doi. org/10.1016/j.desal.2004.07.038

VOURCH, M.; BALANNEC, B.; CHAUFER, B.; DORANGE, G. Treatment of dairy industry wastewater by reverse osmosis for water reuse. Desalination, Amsterdan, v. 219, n. 1-3, p. 190-202, 2008. http://dx.doi.org/10.1016/j.desal.2007.05.013 